\title{
ANALISIS KETIMPANGAN DISTRIBUSI PENDAPATAN DI KABUPATEN TAPANULI UTARA
}

\author{
Kijo Sinaga \\ Program Pasca Sarjana Universitas Negeri Medan \\ Jl. Williem Iskandar Ps. V Medan 20221, Telp. 061-6613365 \\ E-mail : kijosinaga@gmail.com
}

\begin{abstract}
The distribution of income is related to the discrepancy of research aims to study the discrepancy level of income distribution at North Tapanuli Regency, to study the Kuznets hypothesis about "Reverse-U Curve", to study the influence of economic growth rate, inflation and rate of open unemployment to the discrepancy level. Theresult of research indicates that the average percentage of the increasing of GRDP based on the basic price in North Tapanuli for 2000-2010 is 14,59 \%. The average of inflation rate is high for 8,72. The average of open unemployment rate is 3,027 \%. The Gini Ratio for North Tapanuli is less than 0,3. This indicates that the score less than 0,3 means the income is distributed evenly. The Reverse- $U$ Curve because requirement of the square equation did not applied at North Tapanuli regency in 2000-2010. Based on estimation, the score of $R^{2}$ is 0,336. Fcalculated $(0,336)$ is smaller than F-test $(18,77)$ means that simultaneously the gross domestic product, inflation and the open unemployment rate did not influence the discrepancy of income distribution. The gross regional domestic product has not a significant influence to the discrepancy of income distribution at North Tapanuli regency. Inflation has not a significant influence to discrepancy of income distribution. The open unemployment rate has not a significant influence to the discrepancy of income distribution at North Tapanuli Utara Regency.
\end{abstract}

Keywords:Gross Regional Domestic Product, Inflation, Open Unemployment Rate, Gini Ratio, Kuznets Curve

\section{PENDAHULUAN}

embangunan ekonomi yang dilaksanakan oleh setiap negara di dunia ini bertujuan untuk meningkatkan kesejahteraan masyarakat di negara tersebut, yang salah satu indikatornya adalah Pendapatan Nasional Per kapita (GNP per kapita). Namun demikian pertumbuhan GNP per kapita yang cepat tidak secara otomatis menambah atau memperbaiki tingkat hidup

QE Journal |Vol.02 - No.03 - 52 
rakyat banyak. GNP saja tidak cukup menjadi indikator satu-satunya untuk kemajuan pembangunan, tetapi yang lebih penting bagaimana, hasil pembangunan tersebut dapat dinikmati oleh segenap penduduk di negara tersebut. Dengan kata lain, bagaimana distribusi pendapatan atau GNP tersebut bagi semua penduduk. Pemerataan pendapatan berarti hasil pembangunan telah dapat dinikmati oleh semua penduduk, termasuk yang berada pada lapisan paling bawah.

Dalam penelitian ini untuk menghitung tingkat pertumbuhan ekonomi daerah digunakan Produk Domestik Regional Bruto (PDRB) perkapita menurut Harga Konstan 2000.

Tabel 1. Pertumbuhan Produk Domestik Regional Bruto Harga BerlakuKabupaten Tapanuli Utara Tahun 2000-2010

\begin{tabular}{ccc}
\hline Tahun & $\begin{array}{c}\text { PDRB } \\
\text { Atas Dasar Harga Berlaku }\end{array}$ & Pertumbuhan (\%) \\
\hline 2000 & $981.051,17$ & 0,105 \\
2001 & $1.111 .851,62$ & 0,133 \\
2002 & $1.283 .783,05$ & 0,155 \\
2003 & $1.523 .401,87$ & 0,187 \\
2004 & $1.746 .623,37$ & 0,147 \\
2005 & $2.155 .279,13$ & 0,234 \\
2006 & $2.418 .455,22$ & 0,122 \\
2007 & $2.729 .499,54$ & 0,129 \\
2008 & $3.126 .116,99$ & 0,145 \\
2009 & $3.392 .626,16$ & 0,085 \\
2010 & $3.807 .803,55$ & 0,122 \\
\hline
\end{tabular}

Sumber : BPS Tapanuli Utara

Berdasarkan Tabel 1.1. terlihat bahwa pertumbuhan PDRB harga berlaku Kabupaten Tapanuli Utara dalam kurun waktu 10 tahun terakhir mengalami peningkatan signifikan. Rata-rata pertumbuhan PDRB harga berlaku di Kabupaten Tapanuli Utara dari Tahun 2000-2010 sebesar 14,21\%. Pada Tahun 2005 PDRB harga berlaku Kabupaten Tapanuli Utara memili nilai tertinggi sebesar 23,39 \% dan terendah terdapat pada tahun 2009 sebesar $8,52 \%$.

Kuznets menyatakan adanya hubungan yang membentuk kurva $U$ terbalik dan data koefisien Gini yang relatif tetap sementara itu pertumbuhan ekonomi yang cukup tinggi maka penulis bermaksud melakukan pengujian tersebut. Melalui kajian ini penulis ingin mengkaji secara empiris apakah pola pertumbuhan ekonomi dan ketimpangan pendapatan di Tapanuli Utara mengikuti pola Kuznets at au tidak. 
Sesuai dengan persoalan yang telah dikemukakan pada bagian terdahulu maka masalah penelitian adalah :

a. Seberapa besar tingkat ketimpangan distribusi pendapatan yang terjadi di Kabupaten Tapanuli Utara?

b. Apakah hipotesis Kuznets tentang Kurva "U Terbalik" berlaku di Kabupaten Tapanuli Utara?

c. Bagaimana pengaruh PDRB, inflasi dan tingkat pengangguran terbuka (TPT) terhadap tingkat ketimpangan yang terjadi di Kabupaten Tapanuli Utara?

Adapun tujuan dari penelitian ini adalah :

a. Untuk mengetahui tingkat ketimpangan distribusi pendapatan yang terjadi di Kabupaten Tapanuli Utara.

b. Untuk mengetahui hipotesis Kuznets tentang Kurva "U Terbalik" berlaku di Kabupaten Tapanuli Utara.

c. Untuk mengetahui pengaruh PDRB, inflasi dan tingkat pengangguran terbuka (TPT) terhadap tingkat ketimpangan yang terjadi di Kabupaten Tapanuli Utara

Untuk memberikan informasi kepada pemerintah dan pihak-pihak terkait lainnya mengenai kebijakan yang akan ditempuh sehubungan dengan pertumbuhan ekonomi dan pola distribusi pendapatan dan memberikan informasi sebagai bahan acuan kepada siapa saja yang ingin melakukan penelitian tentang masalah ini.

\section{METODE PENELITIAN}

Penelitian ini hanya meliputi hubungan pertumbuhan dan ketimpangan pendapatan di Kabupaten Tapanuli Utara. Diketahui bahwa kecamatan yang ada di Kabupaten Tapanuli Utara setelah pemekaran menjadi sebanyak 15 kecamatan. Kecamatan hasil pemekaran baru termasuk dalam pembahasan ini. Permasalahan yang akan dibahas adalah hubungan antara pertumbuhan ekonomi dan ketimpangan pendapatan.

Data yang akan diolah dan dianalisis berupa data sekunder. Data ini bersumber dari instansi atau lembaga terkait dengan permasalahan yang sedang diteliti antara lain dari buku Statistik Tahunan Badan Pusat Statistik (BPS) dan Nota Keuangan dari Departemen Keuangan. Data yang digunakan dalam penelitian ini adalah data time series pada periode tahun 2000 sampai dengan tahun 2010.

Data yang yang digunakan dalam penelitian ini adalah data sekunder yang dikumpulkan dari berbagai publikasi baik lembaga pemerintah maupun swasta. Data tersebut meliputi Gini ratio (Indeks Gini), PDRB harga berlaku dan PDRB harga konstan 2000, Inflasi dan Tingkat Pengangguran Terbuka (TPT).

QE Journal |Vol.02 - No.03 - 54 
Agar tujuan penelitian ini dapat dicapai dan sekaligus menghilangkan makna ganda maka semua variabel yang digunakan dalam penelitian ini harus dirumuskan dengan jelas. Untuk itu, variabel-variabel tersebut dirumuskan sebagai berikut:

a. Ketimpangan distribusi pendapatan adalah ketidakmerataan hasil pembangunan suatu daerah atau negara baik yang diterima masing-masing orang ataupun dari kepemilikan faktor-faktor produksi dikalangan penduduknya.

b. Produk Domestik Bruto adalah merupakan output pada sektor ekonomi dan melihat pertumbuhan di suatu wilayah tertentu

c. Inflasi adalah kecenderungan dari harga-harga untuk naik secara umum dan terus menerus

d. Tingkat Penganggurang Terbuka (TPT) adalah proporsi angkatan kerja yang tidak bekerja dan mencari pekerjaan.

e. Gini Ratio adalah menggambarkan ketimpangan distribusi pendapatan. Kriteria Gini ratio adalah lebih kecil dari pada 0,4 adalah tingkat ketimpangan rendah, antara 0,4-0,5 adalah tingkat ketimpangan moderat dan lebih tinggi dari pada 0,5 adalah tingkat ketimpangan tinggi.

f. Kurva Lorenz merupakan gambarn bentuk garis lengkung untuk mengetahui pengukuran tingkat ketimpangan atau ketidakmerataan dengan cara menghitung rasio bidang yang terletak antara garis diagonal.

g. Kurva Kuznets yang didasarkan atas data time series, yang menekankan hubungan pertumbuhan ekonomi dengan pembagian pendapatan.

Untuk mengetahui tingkat ketimpangan pertumbuhan ekonomi di Kabupaten Tapanuli Utara menggunakan formulasi Indeks Gini Ratio :

$$
\mathrm{n} \text { IG }=1-\sum_{1}\left(X_{i}-X_{i+1}\right)\left(Y_{i}+Y_{i+1}\right)
$$

atau :

$$
\mathrm{n} \text { IG }=1-\sum_{1} \mathrm{f}_{1}\left(\mathrm{Y}_{\mathrm{i}}+\mathrm{Y}_{\mathrm{i}+1}\right)
$$

atau :

$$
I G=f\left(Y_{i}\right)
$$

Dimana :

IG = Indeks Gini Ratio

$\mathrm{X} \mathrm{i}=$ Proporsi jumlah rumah tangga kumulatif dalam kelas $\mathrm{i}$

$\mathrm{fi}=$ Proporsi jumlah rumah tangga dalam kelas $\mathrm{i}$

$\mathrm{Yi}=$ Proporsi jumlah pendapatan rumah tangga kumulatif dalam kelas i

QE Journal |Vol.02 - No.03 - 55 
Banyak model telah digunakan dalam penelitian sebelumnya untuk menjelaskan hubungan antara pertumbuhan ekonomi dan ketimpangan pendapatan.

Kuznets menghipotesiskan bahwa hubungan pertumbuhan ekonomi dan ketimpangan pendapatan membentuk suatu kurva U-terbalik.

Ada beberapa permasalahan yang akan terjadi pada model regresi linier yang secara statistik permasalahan tersebut dapat mengganggu model yang telah ditentukan, bahkan dapat menyesatkan kesimpulan yang dapat diambil dari persamaan yang terbentuk. Untuk itu perlu melakukan uji penyimpangan asumsi klasik,yang terdiri dari : (Insukindo, 2000)

Multikolinearitas adalah hubungan yang sempurna antara beberapa atau semua variabel bebas $(X)$ dalam model regresi yang digunakan. Jika terjadi multikolinearitas yang serius di dalam model maka pengaruh masing-masing variabel bebas $(X)$ terhadap variabel tidak bebas tidak dapat dipisahkan, sehingga estimasi yang diperoleh akan menyimpang (bias).

Heterokedastistas adalah asumsi dalam regresi dimana varians dari residual atau kesalahan tidak sama untuk satu pengamatan ke pengamatan lain. Untuk medeteksi adanya heteroskedastisitas dalam model penelitian ini dilakukan dengan menggunakan Uji Park test, dengan jumlah autoregresive term dua. Jika nila $t$ hitung lebih kecil dibandingkan $t$ tabel hipotesis tidak adanya heteroskedastitas (atau terjadi homokedastisitas) dapat diterima. (Manurung, et al, 2005).

Salah satu cara untuk mendeteksi ada tidakny a autokorelasi digunakan metode Uji Durbin-Watson (Uji DW), dengan rumus :

$$
d=\frac{\sum\left(\mu_{1}-\mu_{t-1}\right)^{2}}{\sum \mu_{t}^{2}}
$$

Dimana nilai DW statistik adalah terletak antara $0-4$, dengan membandingkan nilai DW statistik terhadap DW tabel.

- $0<\mathrm{DW}$ statistik $<d_{L}$; tolak $\mathrm{H}_{0}$ ar tinya tidak ada autokorelasi.

- $d_{L}<$ DW statistik $<d_{U}$; tidak ada autokorelasi positif (inconclusive).

- 4 - $d_{L}<$ DW statistik $<4$; tolak Ho artinya tidak ada autokorelasi.

- 4 - $d_{u}<$ DW statistik $<4-d_{L}$; tidak ada autokorelasi negatif.

\section{HASIL DAN PEMBAHASAN}

Hasil penelitian dalam penelitian ini adalah merupakan hasil dari penulurusan data time series dari variabel-variabel yang diteliti dalam model analisis

QE Journal |Vol.02 - No.03 - 56 
ketimpangan distribusi pendapatan di Tapanuli Utara, yaitu PDRB, inflasi dan tingkat pengangguran terbuka (TPT) dan gini ratio.

Baik buruknya tingkat kesejahteraan secara keseluruhan belumlah lengkap jika tidak diketahui bagaimana pola penyebaran dari pendapatan/pengeluaran tersebut di masyarakat pada suatu daerah/wilayah menurut waktu tertentu. Dengan hanya melihat tingkat kesejahteraannya secara umum tanpa melihat bagaimana pembagian pendapatan/pengeluaran tentunya akan dapat menyesatkan terutama bagi pengambil keputusan (decision maker) dalam mengatasi ketimpangan pendapatan di daerah/wilayah. Masalah ketimpangan pembagian pendapatan tersebut akan terus berlangsung jika tidak ada upaya yang secara khusus diarahkan untuk memberdayakan masyarakat yang berada pada posisi yang kurang beruntung.

Jika dibandingkan dengan tahun 2000 dimana angka Gini Ratio pada tahun tersebut sebesar 0,262 dengan keadaan tahun 2010 sebesar 0,255 yang berarti peningkatan pemerataan pendapatan di Tapanuli Utara semakin membaik pada tahun 2010. Untuk lebih memudahkan dalam melihat tingkat pemerataan di Kabupaten Tapanuli Utara dan Sumatera Utara pada tahun 2002 dan 2003 seperti pada tabel 4.10 .

Masalah pertumbuhan dan ketimpangan pendapatan telah dikemukakan oleh Profesor Simon Kuznets. Kuznets telah berjasa besar dalam mempelopori analisis pola-pola pertumbuhan. Kuznets telah mengemukakan bahwa, dalam jangka panjang pada tahap-tahap pertumbuhan awal distribusi pendapatan atau kesejahteraan cenderung memburuk, namun pada tahap-tahap berikutnya hal itu akan membaik. Observasi inilah yang lalu dikenal secara luas sebagai konsep Kurva, Kuznets "U-terbalik". Konsep tersebut memperoleh namanya, dari bentuk rangkaian perubahan longitudinal (antar waktu) atas distribusi pendapatan (yang diukur berdasarkan koefisien gini) sejalan dengan pertumbuhan GNP per kapita Hipotesa Kuznets merupakan suatu hubungan yang dihasilkan oleh perubahanperubahan jangka panjang dalam struktur ekonomi. Tapi akhir-akhir ini hal mengenai hipotesa Kuznets sering difokuskan pada gejala-gejala jangka pendek. Karena laju pertumbuhan ekonomi yang tinggi di suatu daerah berkembang telah diamati dalam selama jangka waktu yang relatif pendek.

Berikut pembuktian bahwa Kurva Kuznets yang berbentuk U terbalik tidak berlaku di Tapanuli Utara.

dapat menjelaskan bahwa persamaan kuadrat diatas bahwa koefisien LnPDRB sebesar -2,807 memiliki nilai lebih besar dari 0 (nol) dan koefisien LNPDRB2 sebesar 0,97 memiliki nilai lebih kecil dari 0 (nol). Maka sesuai dengan syarat pembuktikan kurva U-terbalik, tidak terpenuhi dengan syarat-syarat tersebut adalah $\beta 1>0$ dan $\gamma 1<0$. Pada Penelitan ini bahwa Hipotesis Kuznets tentang Kurva

QE Journal |Vol.02 - No.03 - 57 
"U Terbalik" tidak berlaku di Kabupaten Tapanuli Utara Nilai Artinya, dalam jangka pendek meningkatnya pendapatan domestik regional bruto (PDRB) tidak diikuti dengan meningkatnya kesenjangan pendapatan.

Teori Kurva U Terbalik dari Kuznets dapat dibuktikan dengan membuat grafik antara PDRB per kapita dengan tingkat ketimpangan antar daerah. Gambar 4.17 merupakan kurva hubungan antara Gini Ratio sebagai sumbu vertikal dengan PDRB harga berlaku sebagai sumbu horizontal di Tapanuli Utara. Berdasarkan gambar tersebut didapatkan bahwa hipotesis Kuznets yang menggambarkan hubungan antara indeks ketimpangan dengan PDRB per kapita yang berbentuk U terbalik tidak berlaku di Tapanuli Utara

Dalam melakukan estimasi model untuk mengetahui pengaruh Produk Domestik Regional Bruto (PDRB), inflasi (INF) dan tingkat pengangguran terbuka (TPT) terhadap tingkat ketimpangan distribusi pendapatan yang terjadi di Kabupaten Tapanuli Utara, penelitian ini menggunakan Metode Kuadrat Terkecil Biasa (Ordinary Least Square=OLS) dimana hasil estimasi OLS terhadap model yang dipakai, disajikan pada Tabel 4.12 dibawah ini. Dengan operasional model penelitian ini adalah sebagai berikut :

$$
\text { IG = 0,223- 0,386PDRB + 0,003INF + 0,007TPT }
$$

dimana :

IG $\quad=$ Indeks Gini di Tapanuli Utara.

PDRB = Tingkat pertumbuhan Ekonomi di Tapanuli Utara.

$\mathrm{INF}=$ tingkat inflasi di Tapanuli Utara.

$\mathrm{TPT}=$ tingkat pengangguran terbuka (TPT) di Tapanuli Utara.

Multikolinearitas adalah hubungan yang sempurna antara beberapa atau semua variabel bebas (X) dalam model regresi yang digunakan. Jika terjadi multikolinearitas yang serius di dalam model maka pengaruh masing-masing variabel bebas $(X)$ terhadap variabel tidak bebas tidak dapat dipisahkan, sehingga estimasi yang diperoleh akan menyimpang (bias).

Adanya gejala heteroskedastisitas pada model penelitian ini, menyebabkan hasil pengujian hepotesis menjadi tidak signifikan. Di dalam penelitian ini gejala heteroskedastisitas dilakukan dengan "Uji Park". Hasil pengujian gejala heterokedastisitas dengan "Uji Park" dapat dilihat pada tabel berikut.

Dari hasil estimasi residual dengan variabel bebas, ternyata semua variabel bebas PDRB, inflasi (INF), dan tingkat pengangguran terbuka (TPT) menjadi tidak signifikan. Hal ini dikarenakan bahwa nilai t-tabel lebih besar daripada t-ratio masing-masing variabel bebas. Maka dapat disimpulkan bahwa hasil estimasi 
model tersebut tidak terdapat gejala heteroskedastisitas. Implikasinya hasil ini dapat diabaikan karena tidak berpengaruh terhadap model yang digunakan.

Salah satu cara untuk mendeteksi ada tidaknya autokorelasi digunakan metode Uji Durbin-Watson (Uji DW), dengan rumus :

$$
d=\frac{\sum\left(\mu_{1}-\mu_{t-1}\right)^{2}}{\sum \mu_{t}^{2}}
$$

Dimana nilai DW statistik adalah terletak antara $0-4$, dengan membandingkan nilai DW statistik terhadap DW tabel.

- $0<$ DW statistik $<d_{L}$; tolak $\mathrm{H}_{0}$ ar tinya tidak ada autokorelasi.

- $d_{L}<$ DW statistik $<d_{U}$; tidak ada autokorelasi positif (inconclusive).

- $4-d_{L}<$ DW statistik $<4$; tolak Ho artinya tidak ada autokorelasi.

- 4 - $d_{u}<$ DW statistik $<4-d_{L}$; tidak ada autokorelasi negatif.

Berdasarkan hasil pengujian autokorelasi terhadap hasil estimasi model penelitian tingkat ketimpangan distribusi pendapatan di Kabupaten Tapanuli Utara bahwa model penelitian tersebut tidak mengalami autokorelasi karena nilai $\mathrm{DW}=1,387$ berada pada daerah keragu-raguan hipotesis null.

\section{SIMPULAN}

1. Nilai Gini Ratio Kabupaten Tapanuli Utara Tahun 2000-2010 berada dibawah nilai dari 0,4 . Hal ini menunjukkan nilai berada dibawah 0,4 menunjukkan distribusi pendapatan yang cukup merata.

2. Hipotesis Kuznets tentang Kurva "U Terbalik" tidak berlaku di Kabupaten Tapanuli Utara

3. Hubungan pertumbuhan Produk Domestik Regional Bruto (PDRB) memiliki tanda koefisien negatif (tidak searah) dan pertumbuhan Produk Domestik Regional Bruto (PDRB) tidak memiliki pengaruh yang signifikan terhadap tingkat ketimpangan distribusi pendapatan di Tapanuli Utara.

4. Hubungan inflasi (INF) dengan tingkat ketimpangan distribusi pendapatan memiliki tanda koefisien positip (searah) dan variabel inflasi (INF) tidak memiliki pengaruh yang signifikan terhadap pertumbuhan tingkat ketimpangan distribusi pendapatan.

5. Hubungan tingkat pengangguran terbuka (TPT) dengan tingkat ketimpangan distribusi pendapatan memiliki tanda koefisien positip (searah) dan variabel tingkat pengangguran terbuka (TPT) tidak memiliki pengaruh yang signifikan

QE Journal |Vol.02 - No.03 - 59 
terhadap tingkat ketimpangan distribusi pendapatan di Kabupaten Tapanuli Utara.

\section{SARAN}

1. Pemerintah diharapkan menetapkan kebijakan-kebijakan perda yang berhubungan dengan bidang pertanian daerah secara hati-hati agar mampu menjaga stabilitas makroekonomi serta memperkuat berguna meningkatkan pertumbuhan ekonomi di masa depan Kabupate Tapanuli Utara.

2. Faktor belanja daerah sektor usaha pertanian seharusnya mendapat perhatian khusus sehingga dapat mempengaruhi kontribusi sektor pertanian terhadap PDRB sektor pertanian menjadi sektor basis di Kabupaten Tapanuli Utara.

3. Penetapan peraturan perundangan-undangan terutama dalam penetapan peningkatan pendapatan asli daerah diharapkan konsisten agar dapat memperlancar kinerja aparat pedesaan.

\section{DAFTAR PUSTAKA}

Aliasuddin, 1998, Aftalisis Disparitas Antar Daerah Tingkat H di Propinsi Daerah Istimewa Aceh, Karya Ilmiah, Fakultas Ekonomi Unsyiah.

Ahmad, 2000, Perubahan Struktur Ekonomi Regional Sumatera Dalam Proses Pertumbuhan Ekonomi Nasional, Disertasi, Universitas Gajah Mada,Yogyakarta

Arsyad, L., 1992, Ekonomi Pembangunan, Edisi ke-2, Sekolah Tinggi Ilmu Ekonomi YKPN,Yogyakarta.

Biro Pusat Statistik, 1996-1999, PDRB Propinsi-propinsi di Indonesia Menurut Lapangan Usaha, Jakarta -Indonesia.

1999, Indikator Kesejahteraan Masyarakat, Biro Pusat Statistik JakartaIndonesia

Boediono, 1992, Teori Pertumbuhan Ekonomi, Edisi 1, BPFE-yogyakarta.

Chenery.H, M.S.Ahluwalia, C.L.G.Bell, J. H.Duloy, and R. Jolly, 1974, Redistribution With Growth, Oxford University.

Chang, J.Y., and R.Ram, 2000,Level of Development, Rate of Economic Growth, and Income Inequality, University of Chicago.

Djojohadikusumo,S., 1994, Dasar Teori Ekonomi Pertumbuhan \& Ekonomi Pembangunan, LP3ES, Jakarta.

Froyen, R. T., 1996, Macroeconomics, Prentice Hall International, New Jersey.

QE Journal |Vol.02 - No.03 - 60 
Gillis, Perkins, Roemer and Snodgrass, 1992, Economics of Development Third Edition, United State of America.

Badan Perencanaan Nasional, 1995, Pembangunan Dalam Angka, BAPPENAS Jakarta.

Gratak, S., 1995,Introduction to Development Economics, Third edition, Cornwall, London.

Gujarati, D, 1993, Ekonometrika Dasar, Alih Bahasa Drs Ak Sumarno Zain,MBA,Erlangga,Jakarta.

Hasibuan, N., 1993, Pemerataan Pembangunan Ekonomi, Cetakan pertama, Universitas Sriwijaya (UNSRI), Palembang.

Norbaiti, 1997, Analisis Distribusi Pendapatan Sektor Informal dan Formal Serta Faktor-faktor yang Mempengaruhinya di Kotamadya Banda Aceh. Tesis (tidak dipublikasikan) Universitas Syiah Kuala.

Susanti, Hera, M. Ikhsan, dan Widyanti, 1995, Indikator-Indikator Makroekonomi, Lembaga Penerbit Fakultas Ekonomi Universitas Indonesia.

Todaro, NU, 1994 Pembangunan Ekonomi di Dunia Ketiga, Alih Bahasa oleh Ir.Burhahanuddin Abdullah, M.A.Erlangga,Jakarta.

QE Journal |Vol.02 - No.03 - 61 